\title{
Heavy metal music meets complexity and sustainability science
}

\author{
David G. Angeler
}

\begin{abstract}
This paper builds a bridge between heavy metal music, complexity theory and sustainability science to show the potential of the (auditory) arts to inform different aspects of complex systems of people and nature. The links are described along different dimensions. This first dimension focuses on the scientific aspect of heavy metal. It uses complex adaptive systems theory to show that the rapid diversification and evolution of heavy metal into multiple subgenres leads to a self-organizing and resilient socio-musicological system. The second dimension builds on the recent use of heavy metal as a critical thinking model and educational tool, emphasizing the artistic component of heavy metal and its potential to increase people's awareness of environmental sustainability challenges. The relationships between metal, complexity theory and sustainability are first discussed independently to specifically show mechanistic links and the reciprocal potential to inform one domain (science) by the other (metal) within these dimensions. The paper concludes by highlighting that these dimensions entrain each other within a broader socialcultural-environmental system that cannot be explained simply by the sum of independent, individual dimensions. Such a unified view embraces the inherent complexity with which systems of people and nature interact. These lines of exploration suggest that the arts and the sciences form a logical partnership. Such a partnership might help in endeavors to envision, understand and cope with the broad ramifications of sustainability challenges in times of rapid social, cultural, and environmental change.
\end{abstract}

Keywords: Auditory arts, Complexity science, Complex adaptive systems, Heavy metal music, Social-ecological systems, Sustainability, Transdisciplinary science, Environmental education, Global change

\section{Background}

What does complexity theory (for definitions of terms in italics see Table 1) tell us about heavy metal music and its links to complex challenges as those present in global environmental sustainability? This question has been inspired by earlier scientific (Bachelard 1934, 1936) and artistic (Breton 1936) writings and recent calls (Angeler et al. 2016), which advocate the connection of isolated knowledge from different disciplines into a broader model of scientific inquiry. Specifically, this paper links the auditory arts, using heavy metal as an example, with two scientific disciplines, one comprising basic science (complexity theory) and the other applied research (environmental sustainability).

*Correspondence: david.angeler@slu.se

Department of Aquatic Sciences and Assessment, Swedish University of Agricultural Sciences, Box 7050, 75007 Uppsala, Sweden
The choice to link heavy metal with two apparently disparately distinct scientific disciplines is on purpose. Isolated knowledge from different disciplines can be linked in different ways and vary in their degree of subjectivity versus objectivity (Ratner 2002), the reciprocity by which one discipline informs the other (Rinia et al. 2002), or research method (qualitative and/or qualitative) used in transdisciplinary research (Angeler 2016). This variability is manifest in the approach used in this paper (Fig. 1), in which links between knowledge domains are made along three dimensions. The first dimension emphasizes the scientific component of heavy metal music (Brown 2011) in which it is linked to complex adaptive systems theory, a branch of complexity science, to describe the emergence of a socio-musicological system (Fig. 1). This paper will scrutinize the reciprocal potential to inform one domain by the other; that is, where heavy metal music potentially contributes to inform complex adaptive systems 


\section{Table 1 Overview and definitions of terms used in this paper}

Term
Complexity theory
Heavy metal music
Environmental sustainability/Sustainability
Science
Science

Complex adaptive systems

Socio-musicological system

Social-ecological system

Non-linear processes

Delays

Feedback loops

Balancing feedback loops

Reinforcing feedback loops

Hierarchical organization

Information flow

Connectedness

Regime shift

\section{Definition}

Encompasses various approaches to the study of complex systems, including the application of complexity theory to strategy and organizations, the complexity of economics, self-organizing complex adaptive systems, chaos theory, theoretical computer science and mathematics and algorithmic information theory

A fast evolving form of the auditory arts belonging to the genre of rock music. Metal has roots in blues rock and psychedelic rock and originated in the late 1960s and early 1970s, mainly in the United Kingdom and the USA. Heavy metal has diversified into more than 20 subgenres with characteristic vocal, rhythm and instrumentation structure (see Table 2). This paper explores the scientific and artistic components of heavy metal to describe aspects of complex systems of humans and nature

The interaction of human population with their environment in ways to guarantee their natural resources needs without compromising the ability of future generations to meet their needs. Sustainable development aims at avoiding overuse or degradation of resources to ensure longterm environmental quality

Hierarchical entities that consist of diverse and autonomous parts or components ("agents") that depend on and relate with each other, and which are linked through many connections. Complex adaptive systems adapt to and learn from changes in the environment, which allows them to self-organize as a unified whole

A particular from of complex adaptive system with reference to music, wherein system adaptation, learning and self-organization are governed by the broader and complex interaction between musicological, psychological, cultural, social, technological, marketing, and other economic aspects of social and technological change

A complex adaptive system of people and nature, where one component influences and is influenced by the other. For instance, the relationship between commercial fisheries, ecosystem service provisioning, resource overexploitation, aquatic resource degradation, loss of economic and social potential

Non-linearity manifests when not all agents in a complex adaptive system interact with the same strength which each other (e.g., species A and B in a system, or $Y$ and Z, or A and Z, and so forth). Also when the loss of an agent in the system (e.g., a key predator in an ecosystem), can cause substantial change in biophysical interactions and a subsequent reconfiguration of the structure and functioning of the system

Delays in complex systems arise from the ability of systems to buffer the impact of disturbances. When the buffering capacity (mediated through feedback loops) is exhausted the delayed impact becomes manifest in structural and functional changes in the system. For instance, habitat degradation may make the persistence of large mammals untenable. However, the effects of degradation may not become evident until these mammals went extinct

Circuits in complex systems that reinvest some of the yield to the input of a system to allow for self-correction and adjustment to internal and external variables

Also known as negative feedback loops. These occur when a changing initial condition lessens its change in the future. For instance, when the population number of predators increases, the consumption of their prey increases too, leading to a decrease in their population numbers. Due to increasing scarcity of prey, the population number of predators decreases as a result of the lack of food. Population dynamics of predator and prey are balanced

Also referred to as positive feedback loops. These occur when a changing initial condition furthers its change in the future. For instance, the greater the population of a species, the more progeny will be born. When those become adults, they will also have offspring. Rapid population growth rates of these species are reinforcing themselves and can ultimately have substantial impact on natural resources

Refers to patterns and processes that occur at discrete scales of space and time. For instance, continental drift acts on millennial time scales and changes the face of the entire globe. By contrast, an annual grass is very short-lived and lives in a narrow space within a meadow

Outcome of interaction between agents in a complex adaptive system that informs and influences the behavior and interaction of other agents in the system. For example, the collapse of the real-estate market in the USA in 2008 provided the "information" which "flew" across the world to affect the global economy at a systemic level

The degree and strength by which agents in a complex adaptive system interchange information based on their interactions. For instance, the economic crisis had a severer effect on southern European countries (strong connection with economic collapse) relative to northern European countries (weaker connection)

A regime shift occurs when a complex system changes from one set of structure, functions and processes to another set of structures, functions and processes. Regimes are stable and a system may not shift back to a previous regime without substantial and costly management 


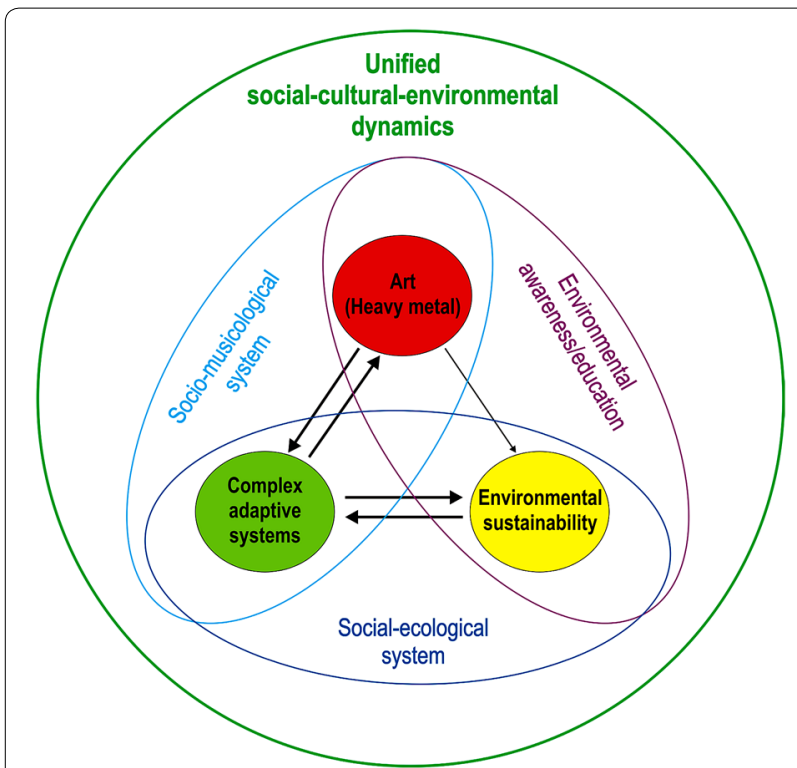

Fig. 1 Schematic showing links between distinct, apparently unrelated knowledge domains. Shown are: (1) The links between heavy metal music and complex adaptive systems theory to describe the emergence of a socio-musicological system (light blue ellipse). (2) The potential of heavy metal music as an educational tool to increase awareness of environmental sustainability challenges (purple ellipse). (3) The links between complex adaptive systems and environmental sustainability that mediate social-ecological system dynamics (dark blue ellipse). (4) An emerging broader, unified picture of social-cultural-environmental dynamics (green circle). Arrow directions and thickness represent reciprocal versus unidirectional information potential between domains and interpretational objectivity versus subjectivity, respectively (see "Background" section)

theory and vice versa (arrows in both direction in Fig. 1). Although this paper will only explore linkages theoretically, it is deemed possible that numerical analysis, which have been used in the study of complex adaptive systems (Holland 2014), might be used to study the heavy metal socio-musicological system. The potential to objectively study socio-musicological systems is shown by thick arrows in Fig. 1.

The second dimension builds on the recent use of heavy metal as a critical thinking model and educational tool (Angeler et al. 2016; Schmaltz 2016), emphasizing the artistic component of heavy metal (Kahn-Harris 2007) and its potential to increase people's awareness of environmental sustainability challenges (Fig. 1). Information potential in this link is unidirectional; that is, heavy metal music informs only sustainability science. This unidirectional connection is made via allegories. These relate the music with specific environmental change challenges and ensuing human tensions with the aim to elicit thought and educate people about, and increase their awareness of environmental change. The thin arrow that symbolizes the unidirectional link (Fig. 1) means that the connection between heavy metal music and sustainability is entirely subjective. The unidirectional link also suggests that environmental sustainability issues currently do not influence metal music in ways to result in integral song architectures (lyrics, singing, rhythms, instrumentation) from which a "sustainability metal subgenre" might emanate. Figure 1 also shows a third dimension, in which complex adaptive systems theory and environmental sustainability are linked to describe the dynamics of complex systems of people and nature (social-ecological systems). The complexity of social-ecological systems dynamics has been reviewed recently (e.g., Allen et al. 2014) and will therefore not be explored here. However, this third dimension will be considered in the broader discussion of the synthesis between heavy metal, complex adaptive systems theory and environmental sustainability.

This paper will be structured in three parts. The first part emphasizes the scientific component of heavy metal music. It briefly sketches the claims of complex adaptive systems theory and then examines metal through the lens of this theory, including the description of operational terms to portray the emergence of a socio-musicological system. The second part of the paper focuses on the artistic component of the music and provides an overview of social-ecological systems challenges that are relevant from the perspective of environmental sustainability. It uses heavy metal songs in which their song architecture becomes allegorical to specific environmental challenges and potentially associated human tensions. These links are discussed within the context of environmental awareness and education. The paper concludes by synthesizing the linkages between the different knowledge domains in an overarching discussion of a broader and more integral understanding of social-cultural-environmental dynamics in times where planet Earth undergoes fast change of climatic, ecological, economic, production, communication and other technological systems (green circle in Fig. 1) (Folke et al. 2002; Berkes et al. 2003; Walker et al. 2004). This paper is intentionally descriptive to provoke thought and provide a source to stimulate future transdisciplinary research and cross-pollinate currently distinct disciplines.

\section{Heavy metal music: a complex adaptive system}

Complex adaptive systems theory, a branch of complexity science, studies the systemic behavior of complex systems that results from the interaction of distinct features, including adaptation, recalibration and self-organization (Holland 2014). Complex adaptive systems dynamics have been described for a plethora of systems, including the cell, brain, and immune system of humans, ecological (social insect colonies, ecosystems, the biosphere), 
economic (global macroeconomic network, stock markets), technological (internet, artificial intelligence), political (geopolitical organizations, terrorist networks) and other social systems (schools, health services) (e.g., Meadows 2008; Holland 2014; Sundstrom et al. 2014). The use of complex adaptive systems theory for explaining the dynamic organization of disparately distinct systems suggests that an examination of metal as a complex adaptive system is worthwhile.

Heavy metal music, a fast evolving form of the auditory arts belonging to the genre of rock music that originated in the late 1960s and early 1970s, mainly in the United Kingdom and the USA, has been regarded in recent years as a cultural esthetic worthy of scientific study in its own right (Brown 2011). This is reflected in an increasing amount of scientific publications (Hickam 2014) since the first scholarly publications by Weinstein (1991) and Walser (1993). During the last 50 years, metal has diversified rapidly into more than 20 subgenres out of traditional or classic heavy metal (Sharpe-Young 2007; Table 2). Nowadays it spans a wide range of song architectures, lyric themes, and instrumentation, including distorted guitars, emphatic rhythms, dense bass-and-drum sound, and vigorous vocals, and the genre at large continues to develop fast (Brown 2011). This development has reached a complexity that is reminiscent of complex adaptive systems dynamics. That is, the development and diversification in metal has been the result of the broader and complex interaction between musicological, psychological, cultural, social, technological, marketing, and other economic aspects of social and technological change (Seppi and Stoycheva 2015), leading to a self-organizing sociomusicological system (Patel 2010).

Meadows (2008) and Holland (2014) give simple overviews of complex adaptive systems, and provide the basic criteria for a relatively uncomplicated examination of metal through the lens of complexity science. My examination of metal as a complex adaptive system is based on a theoretical model because of two reasons. First, metal is a very young field with many gaps in the scientific literature, and it currently lacks the necessary broader peer-reviewed quantitative and qualitative information to populate/ parameterize models empirically and realistically. Second, even if this knowledge was available, model predictions are highly uncertain because, as noted by Holland (2014), a full description/understanding of complex adaptive systems is impossible. There is, for instance, emergent behavior that cannot be described by the sum of individual components, which often results from non-linear processes, delays, and complex feedback loops (see descriptions and examples in Table 1). However, theoretical models have value in building a foundation for future research (Meadows 2008).
My theoretical model of the metal socio-musicological system is based on the description of the general elements that make up a complex adaptive system (Fig. 2). Basic elements of a complex adaptive system are: hierarchical organization, information flow within and between these hierarchies and other complex systems (i.e., connectedness), non-linear patterns and delays resulting from information flow, and the deriving reinforcing and balancing feedback loops (Meadows 2008; Holland 2014). These feedback loops comprise the manifold processes that drive system behavior, and help the system recalibrate and adapt to disturbance. From these basic system elements emerge innovation and learning, resilience, selforganization and system-level persistence.

\section{Hierarchical organization}

The hierarchical organization of the metal complex adaptive system is based, from a structural point of view, on a series of "actors" and begins with the musician at the lowest operational level. Lowest operational level means that there are more levels down the hierarchy; that is, musicians as humans are built up of organs, cells, organelles, molecules and atoms but these levels are likely marginal for the understanding of the metal complex adaptive system. The structure of the complex adaptive system increases in complexity with increasing hierarchical level, which is reflected in an increasing number of actors. That is, the next level up the operational hierarchy of the metal complex adaptive system is the band comprising various musicians. Various bands playing similar musical styles collectively comprise the subgenre, the next level in the hierarchy (Table 2; Fig. 2). The highest operational level is the genre of heavy metal music. This level is not only composed of the plethora of musicians and bands across the multiple subgenres but also other actors from distinct social environments that interact with each other. These include fans, music producers, technologists, scientists from different fields (e.g., culture and art studies, anthropology, psychology), marketing professionals, and politicians. Combined, this broader community of different actors makes up the socio-musicological system that comprises the metal complex adaptive system. There are further levels up the hierarchy (e.g., the whole biosphere); however, these may go beyond the upper boundaries necessary for describing the structure of agents and thus the highest operational hierarchies of the metal complex adaptive system. This does not mean, however, that there aren't functional linkages (some of these will be explored in the Synthesis section). That is, if the whole biosphere undergoes significant biophysical change it is likely that it will affect all the levels subsumed within it. 


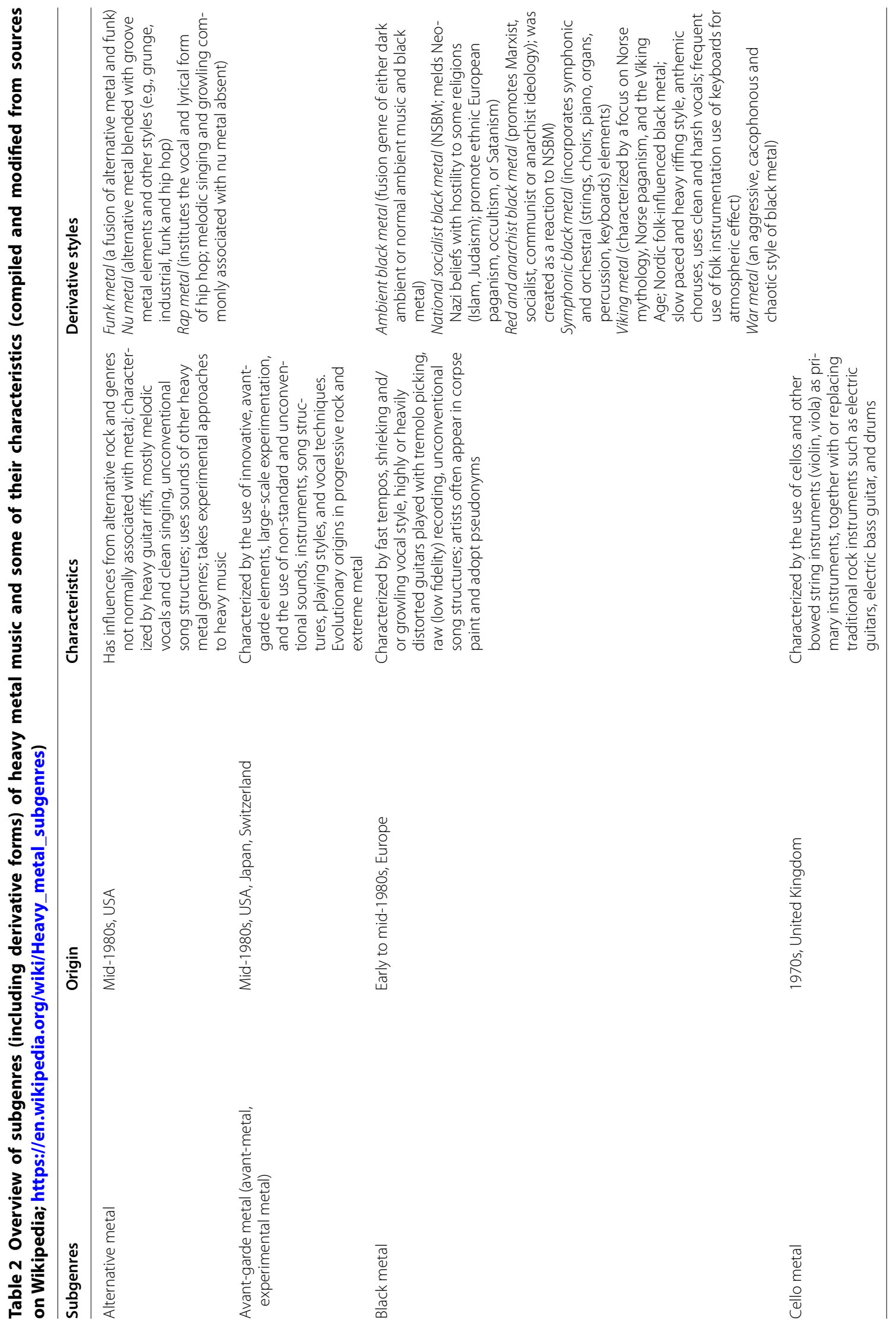



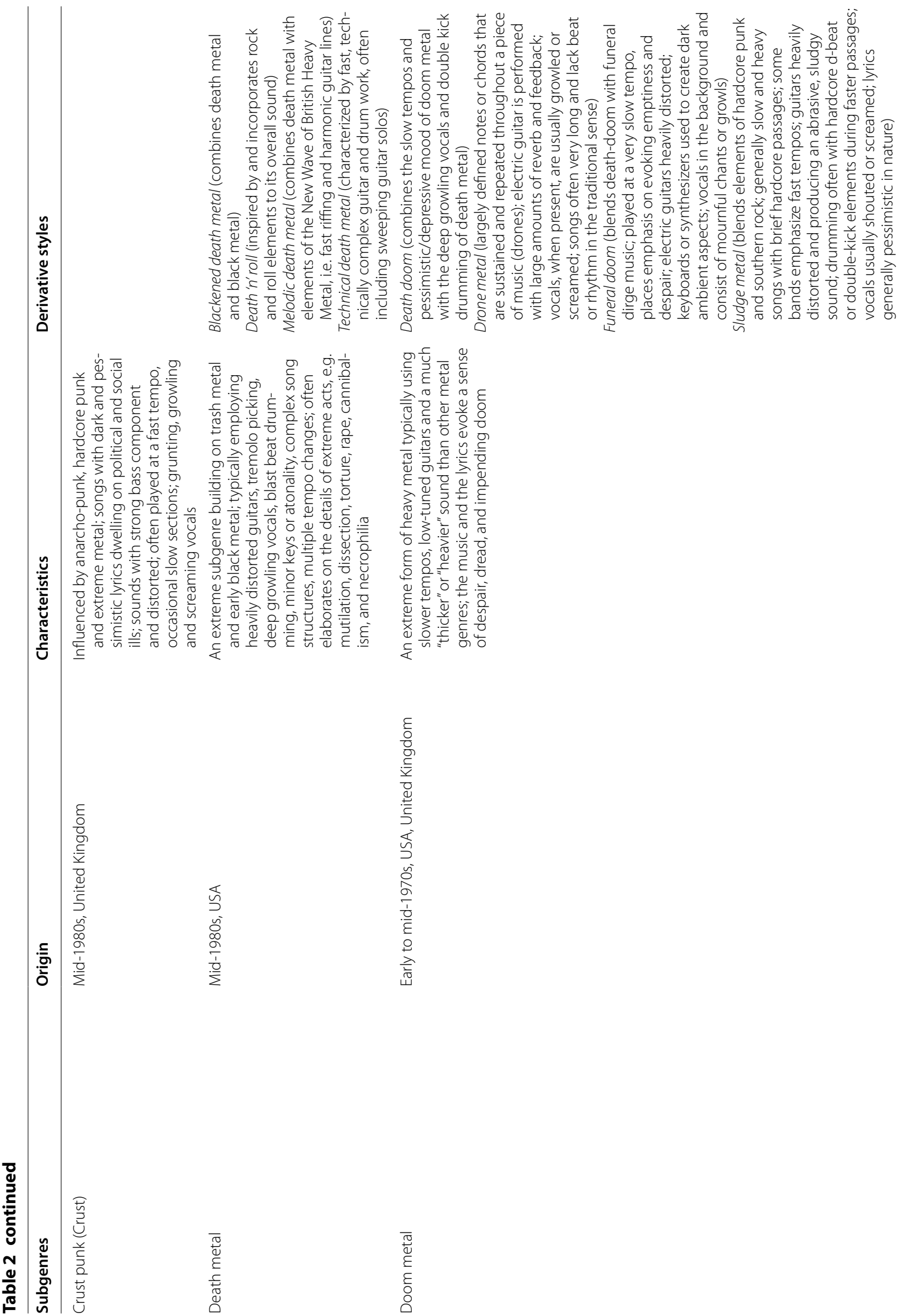


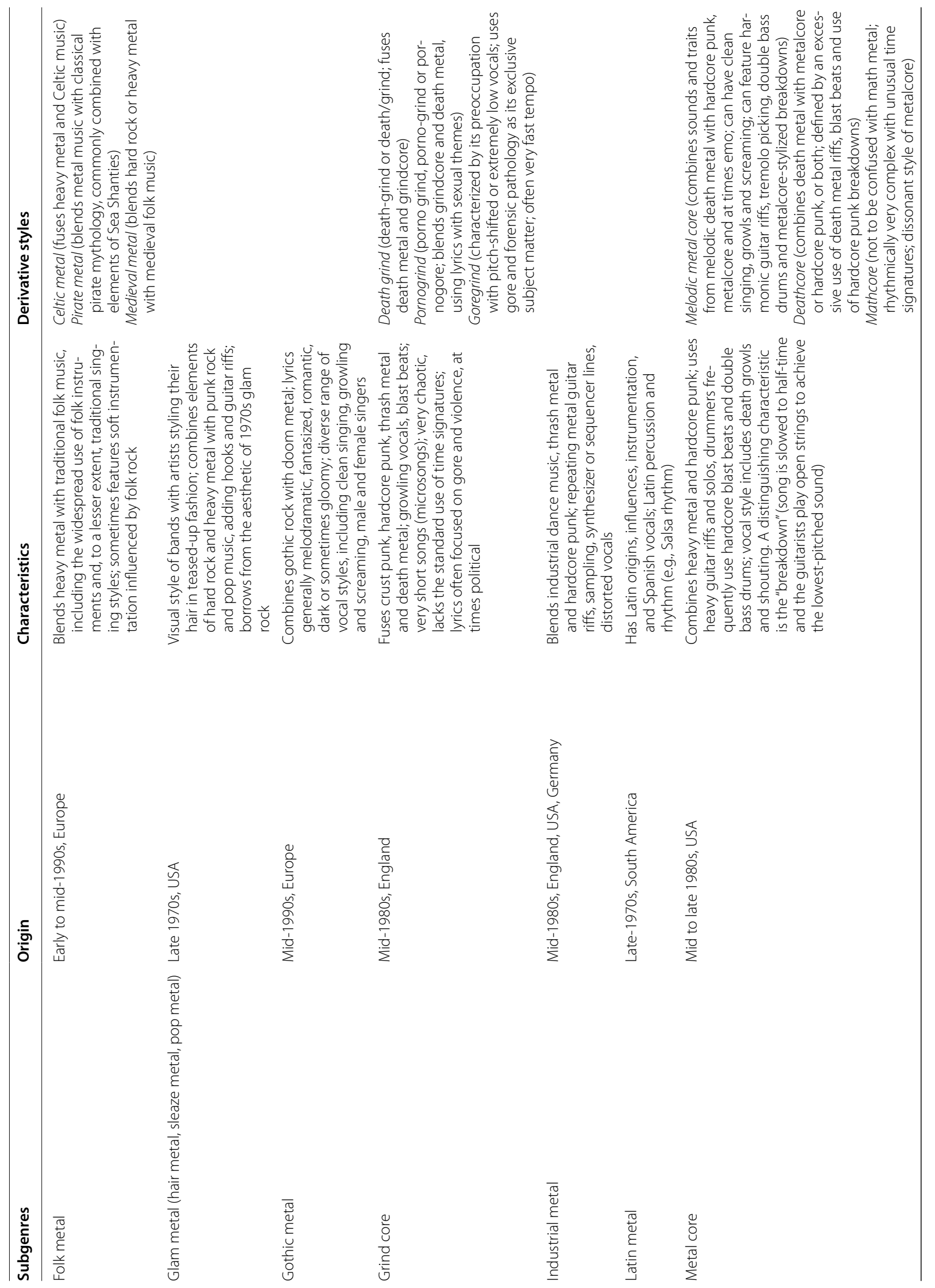




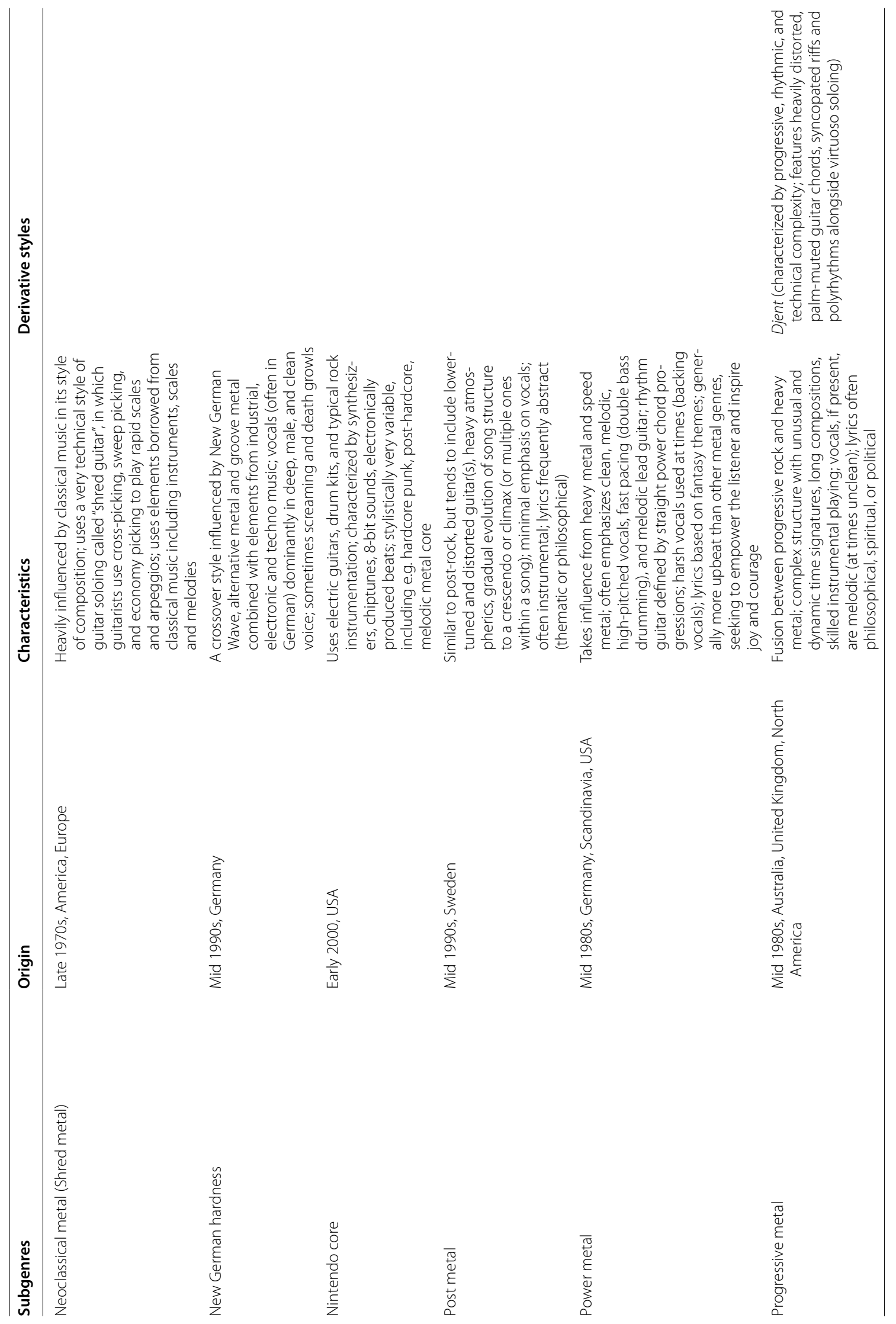



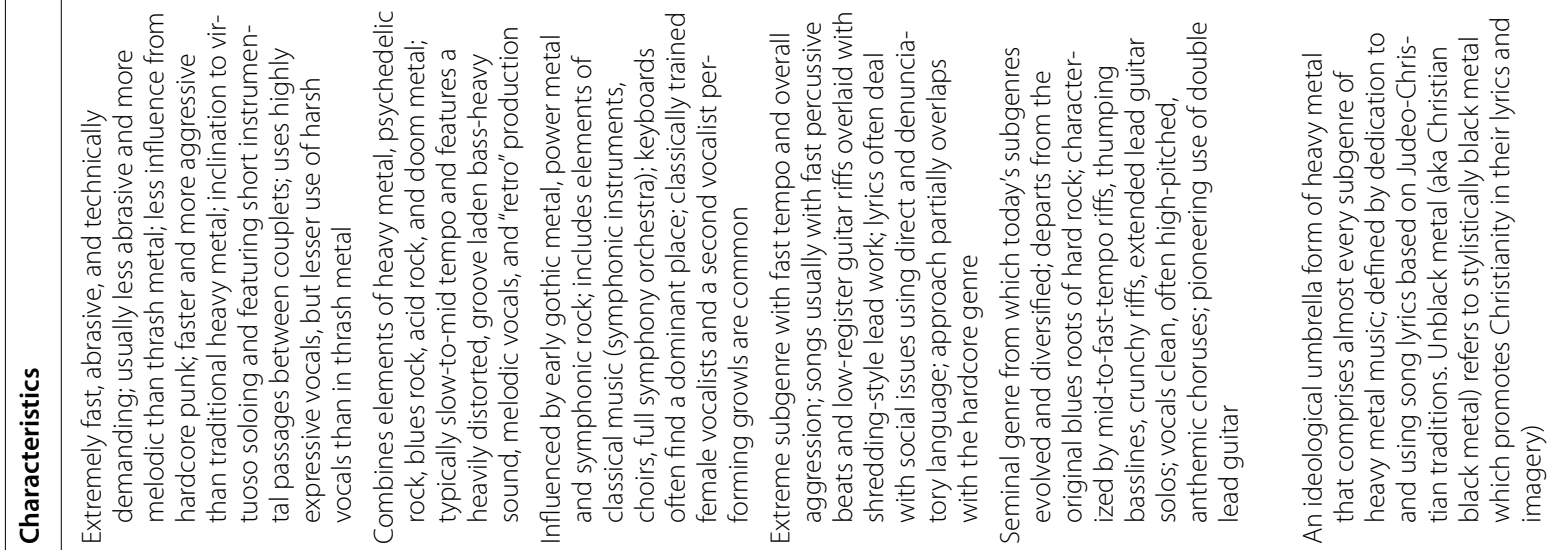

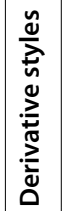

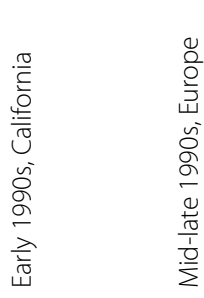

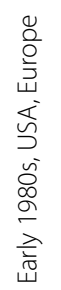

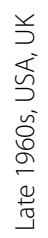

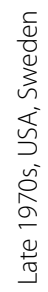

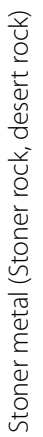

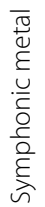

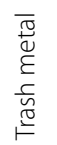

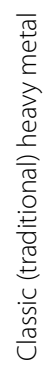

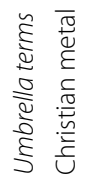


Angeler Springerplus (2016)5:1637

age 10 of 20

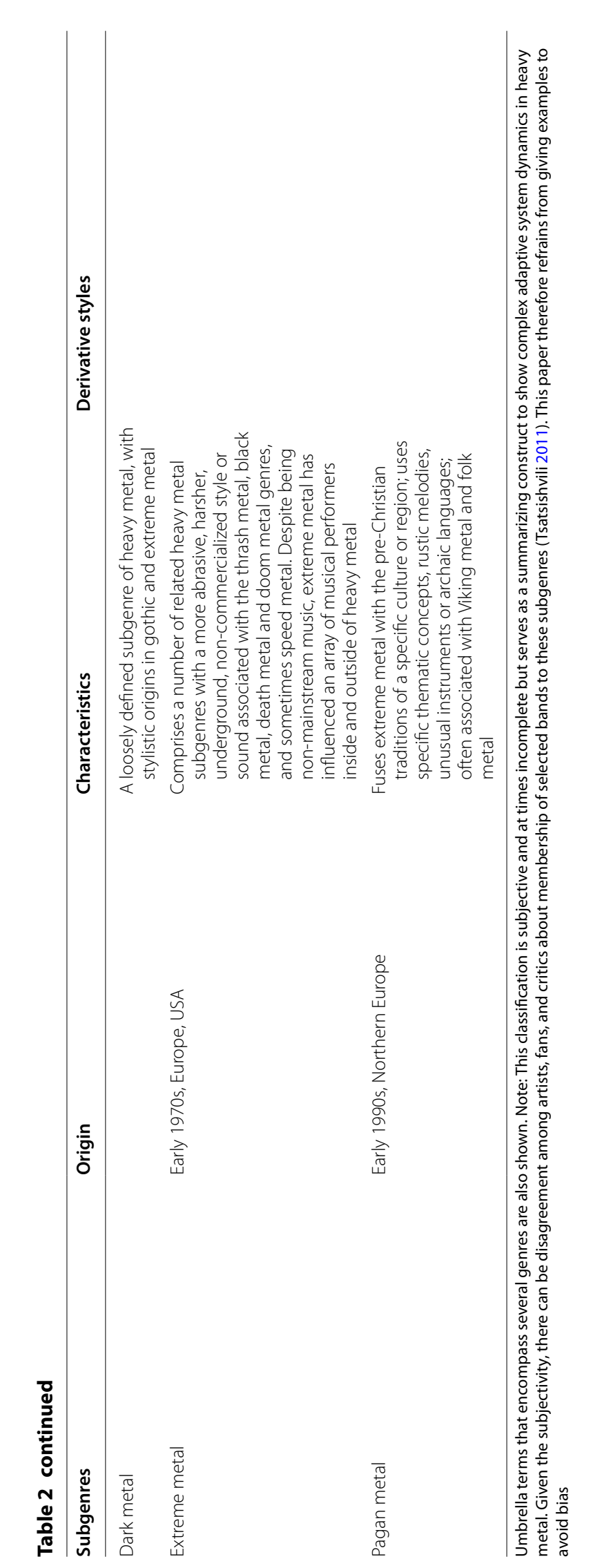




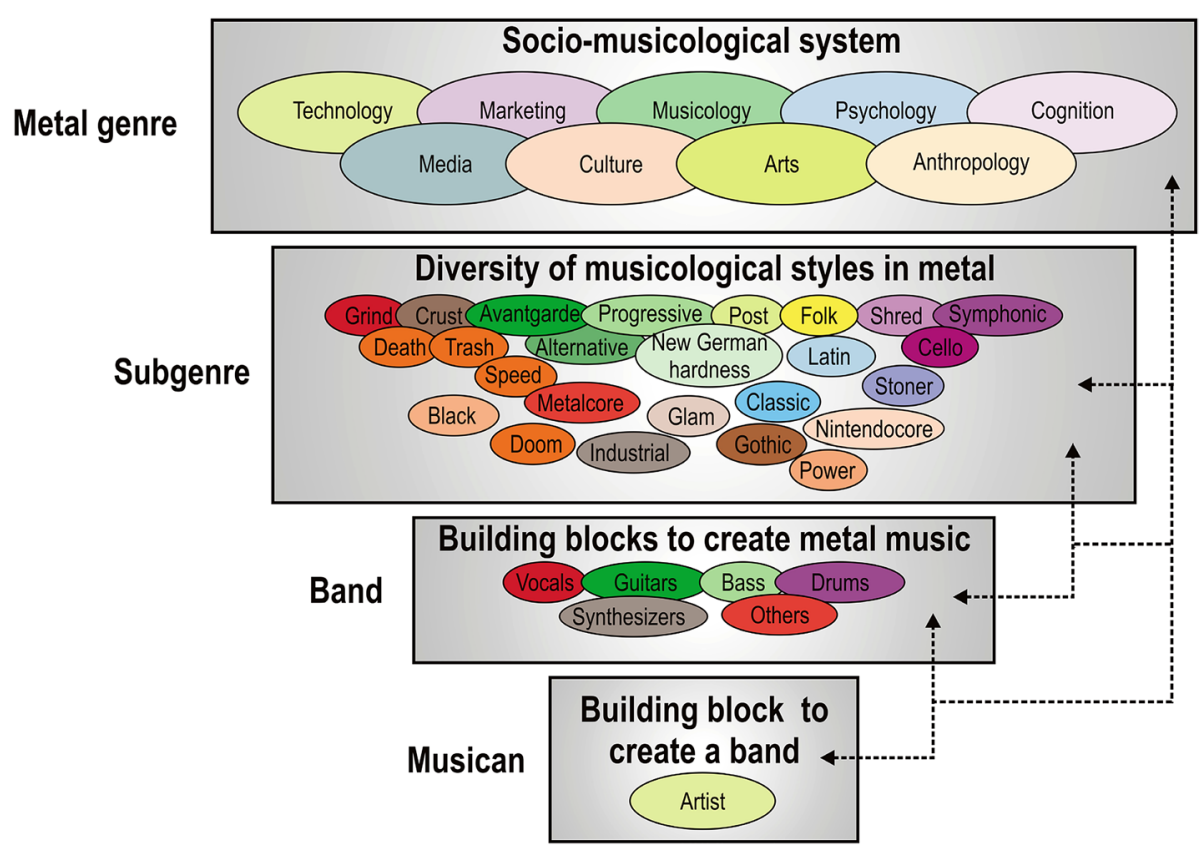

Fig. 2 Simplified complex adaptive system model of heavy metal music showing discrete hierarchical structure and the connections between those. Non-linear interactions (connectivity between agents) are symbolized by different colors. These colors are not an absolute representation of dynamic interactions and only serve to visualize non-linear system connectivity; interactions and similarities are therefore not an absolute representation of dynamic interactions in the heavy metal complex adaptive system

\section{Information flow}

Information flow and connectedness among the structural agents in complex adaptive systems is critical for system function and behavior. Connectedness reflects the structural linkages between agents in the complex adaptive system; these linkages can vary in strength and connect some agents more and others less in the system. For instance, musicians in a band are closer connected to each other than with the musicians of another band. Information flow reflects the functional linkages between the connected agents. That is, the "information" created from the vocalists, guitarists and drummers "flows" between the musicians and leads to the emergence of a song. This example shows that information flow in complex adaptive systems is goal oriented. Specifically, in the metal complex adaptive system it is the generation of a specific form of music that often reflects transgressive cultural and political norms and values (Kahn-Harris 2007; Brown 2011). These norms and values often build on the incorporation of pornographic and forensic themes in their lyrics (e.g., pornogrind, grindcore; Table 2). To this end, agents need to be connected within and across hierarchical levels (Allen et al. 2014), but these connections follow certain rules and vary in strength. In the metal complex adaptive system, individual musicians either act as front man, play the guitar, bass, drums, occasionally synthesizers, and sometimes subgenre specific instruments (Table 2). The rule is that different combinations of these musicians are needed to qualify as a metal band that generates that specific style of music (metal; not classical music). A choir composed of only singers does not qualify as a metal band that plays metal music.

At the band level of the metal hierarchy, the information flow, which comprises the distinctive and characteristic series of sound structure that emerges from the combination of vocals and instruments, is manifested in a song architecture that characterizes the band's label. For instance, doom metal bands typically use slower tempos, low-tuned guitars, and "thicker" or "heavier" sound than other metal subgenres, and the music and lyrics evoke a sense of despair, dread, and impending doom. In metalcore and deathcore, a harsher version of metalcore, a distinguishing characteristic is the breakdown, whereby the song is slowed and the guitarists play open strings to achieve the lowest-pitched sound. Folk metal blends heavy metal with traditional folk music, including the widespread use of folk instruments and, to a lesser extent, traditional singing styles. These examples show the higher within-subgenre similarity rather than between-subgenre similarity of band styles, and more broadly how subgenres are connected. Metalcore and deathcore with their breakdowns are more similar to each other than to death metal and trash metal without breakdowns. However, when compared with symphonic 
metal and classic metal, which are more melodic subgenres, the former metal subgenres become more similar to each other with their overall harshness and aggression. Sometimes metal subgenres are so similar to each other that it is difficult to draw boundaries (Tsatsishvili 2011). As a result, some umbrella terms have been defined that unite similar metal subgenres (Table 2).

That agents in a complex adaptive system are linked and information flows with different strengths among agents reflects another critical hallmark of complex adaptive systems, their nonlinear patterns and processes. Such non-linearity can be seen in different patterns of connection of elements of the metal complex adaptive system. For instance, from a scientific viewpoint, many papers dealing with metal have been published in psychology, meaning that there is high information flow and connectedness between metal and psychology (Brown 2011). To my knowledge none exists between the music and complexity and sustainability science, highlighting the lack of connectedness and information flow between these domains. There is no linear relationship when comparing connectedness in these examples. Similarly, from a cultural-political perspective, Western music is more connected to metal than middle Eastern cultures, in which this form of music doesn't meld well with cultural, religious and ethical belief models (Stanton et al. 2012). Metal is emerging in countries in Asia and Latin America (Wallach 2005; Varas-Díaz et al. 2014), and this emerging link suggests an increasing degree of connectedness of these countries with metal.

Connectedness also has a temporal, dynamic dimension, operating at different speeds across hierarchical levels in the metal complex adaptive system. A metal song typically lasts from seconds to minutes. A subgenre needs years to develop. Metal has now evolved over the past 5 decades. These temporal patterns are also nonlinear, and can comprise a feature characteristic of complex adaptive system dynamics: delays (Table 1). The different speeds also have implications when delays can be perceived. A delay in a complex adaptive system becomes evident when accumulated structural and functional changes in the system suddenly become evident (Table 1). At the song level, such delays are often manifested in unusual time signatures, resulting from unrhythmic patterns when sound elements are synchronized or unsynchronized with lags. This is a characteristic of mathcore, grindcore, and progressive metal. In songs from these subgenres rhythmic delays can be perceived immediately. Other metal subgenres (symphonic metal, power metal) are more melodic and are therefore characterized by fewer rhythmic delays.

At the other extreme, at the highest operational level, the perception of delays might not be easy because current system dynamics operate so slowly that their effects eventually manifest in the future, as is the case with substantial biophysical change in social-ecological systems (Folke et al. 2004). Metal is currently seeing transforming social perceptions and music industries. Music digitalization, rapid popularization of online streaming services (YouTube, Spotify, Facebook, SoundCloud), subscription models, and social media websites facilitate broad exposure. Quickly expanding regional and global metal markets, festivals, and conferences enable social engagement worldwide (Seppi and Stoycheva 2015). In this regard, metal shows a similar "teleconnection" as social-ecological systems (Adger et al. 2009). That is, geographically disparate regions are becoming increasingly connected and one region may affect another remote area due to this global connectivity (e.g., metal styles that have emerged in Sweden [djent] may inspire metal in the USA and elsewhere). In social-ecological systems, for example the production of food and fiber shows similar teleconnection (Rist et al. 2014).

It is clear that the globalization of metal, and music in general, can lead to novel interactions. A case in point is the interaction of metal with other musical genres or sounds from emergent technologies. Nintendocore exemplifies how chiptune elements and other sounds from video gaming (a technological invention) can entrain heavy metal music, leading to a new subgenre. Alternative metal, especially its crossover forms rap metal and nu metal, incorporate elements from hip hop music, a form of contemporary music characterized by rapping (chanted rhythmic and rhyming speech). On the other hand, symphonic metal and cello metal emphasize a strong classical component, particularly in terms of instrumentation used.

Metal is influenced by other genres, but also affects other musical genres. For instance, certain metal elements are reflected in brostep, an emergent form of dubstep, which is a genre of electronic dance music. These interactions between metal subgenres and other music forms and technological inventions exemplify a vast potential and source of dynamic interactions between complex adaptive systems (Kahn-Harris 2007; Brown 2011). These dynamic interactions often follow from the constant recalibration of a complex adaptive system in response to a changing environment. However, the outcomes of these dynamics are currently highly uncertain, partly because of delayed responses that might arise from these interactions. Delays, or time lags, also make predictions of when and why systems are changing extremely challenging.

Uncertainty, highlighted in the above examples, is a general phenomenon in complex systems dynamics. It stems from the stability of current patterns and processes 
in a resilient complex adaptive system. Resilience refers to the ability of a system to maintain structures and functions in the face of disturbances, and when this capacity is exceeded systems reorganize into a new regime with different structures and functions (Holling 1973). Critical to the understanding of resilience are feedbacks, or feedback loops, that arise from the flow of information and connectivity in the complex adaptive system.

\section{Feedback loops}

As is the case with many complex adaptive systems (Sterman 1994), there are potentially far more feedbacks in the metal socio-musicological system than can be currently envisioned and enumerated in this paper. However, some examples shall help make the point that feedback loops essentially contribute to complex adaptive system dynamics in metal.

There are reinforcing and balancing feedback loops, and these can operate within and across hierarchical levels in the complex adaptive system and affect processes from both directions in the loop (Meadows 2008). Imagine at the band level agreement among musicians and similar opinions about music style and where to perform concerts. Based on these criteria, bands compose new songs and make a new release or concert. After each release or gig the band composes new songs and releases a new album and presents it at another festival. The band works in a balancing feedback loop, whereby the generation of new music is partly contingent on the music created before. In this calibration process, the musicians and the band at large learn, and this learning process builds the source for future experimentation and innovation. A reinforcing feedback loop becomes evident when there is disagreement and escalating conflict between band members; that is, the reinforcing feedback loop results in an initial conflict that increases over time to further even more conflict in the future. Less cooperation can lead to less songs being produced and consequently fewer releases and/or concerts. With increasing escalation of conflict learning, experimentation and innovation is de-emphasized, contributing to a downward spiral that can culminate in the band's dissolution. There can be of course other factors (personal, professional) leading to the disappearance of a band.

Balancing and reinforcing feedbacks at the band level may scale up to the next hierarchy, the subgenre level of metal. When balancing feedback loops dominate over reinforcing feedback loops, the whole subgenre is likely to persist and further develop. If the relationship is inverse, a subgenre likely disappears. Balancing and reinforcing feedback loops have influenced metal subgenres distinctly. For example, many subgenres see a rapid diversification into derivative styles, based on the constant recalibration resulting from learning that balances feedback loops. For instance, alternative metal diversified into nu metal and funk metal, and death doom, drone metal, funeral doom, and sludge metal derived from doom metal (Table 2). The New Wave of British Heavy Metal that peaked between 1975 and 1985 and which has seen posterior reformation exemplifies that feedback loops can change over time.

Broader social-political environments can exemplify feedback loops at the highest operational hierarchies. Western countries do not generally impose restrictions on cultural, artistic, and scientific development within permitted legal settings. This contributes to and facilitates recalibration, innovation and progress across social environments, and ultimately systemic evolution. As stated before, there are many feedbacks operating between the constantly developing scientific, musicological, economic and marketing aspects in the metal sociomusicological system that ultimately allows it to evolve. On the other hand, in many countries with conservative politics or specific belief models there are more restrictions to development. Progress is often limited due to suppressive and penalizing action that may reinforce incompatibilities between cultural models. Such incompatibilities can be reinforced to such an extent as to lead to violent action, as witnessed during the recent terror attacks at a metal concert in Paris. So too, is the use of heavy metal (and children's TV programs Barney and Sesame Street) in psychological operations used in a negative context, for instance during the interrogation of detainees (BBC 2003) that can reinforce hard feelings towards metal. These examples highlight that top hierarchies are connected to and influence behavior at lower levels.

In short, metal has seen an expansion and gain in world-wide popularity (Trilling 2007), despite some periods of turmoil in the 1990s that forced musicians to distance themselves from the genre, due to a plethora of factors including aversion by the media and music industry (Konow 2002). Despite this, metal has been resilient to this disturbance. It shows that balancing feedback loops have dominated over reinforcing feedback loops thus far in the evolution of metal.

In summary, the broader dynamics of metal abides within a dynamic state space that adapts and flexes constantly based on the complex interaction of agents in the system (Lansing 2003; Frenken 2006), dynamics which can be seen in art at large (Levine and Levine 2011). Social theory on diffusion of art forms shows that some elements climb up and thrive in this state space, and others fizzle out as dead ends based on the structure of social interactions (reminiscent of the viral dynamics of marketing; Leskovec et al. 2007). The state space of the metal 
socio-musicological system comprises similar complex dynamics driven by endogenous and exogenous factors (social perception, changes in music production and routes of exposure, human behavioral, cognitive, and cultural aspects) and interactions. Ultimately, these dynamics highlight the ability of the metal complex adaptive system to persist in broader social and cultural environments. It has become a self-organizing, self-maintaining, resilient socio-musicological system.

\section{Metal and environmental sustainability}

The previous section emphasized the scientific component of heavy metal music (Brown 2011) and explored its merger with complexity science to describe the emergence of a complex socio-musicological system. This section uses an independent line of inquiry. It emphasizes the artistic component of heavy metal and explores its use as an educational tool to increase people's awareness about environmental sustainability challenges on planet Earth that undergoes fast change in climate, ecological, economic, production, communication and other technological systems (i.e. global change) (Folke et al. 2002; Berkes et al. 2003; Walker et al. 2004). The use of metal music as a critical thinking and educational tool has been recently highlighted (Angeler et al. 2016, Schmaltz 2016).

Sustainability science is concerned with the ability of systems of people and nature to adapt to changing social-environmental baselines (Kates et al. 2001). Natural disasters (floods, wildland fires, hurricanes, infectious diseases), terrorism, or mass migrations of people due to humanitarian crises have increasingly shattered the world in recent years. In its extreme form, the entire globe can undergo a fundamental reorganization because of the broader overexploitation of resources and climate change (Rockström et al. 2009; Hughes et al. 2013). There is much uncertainty about global change outcomes, but negative consequences (conflicts, health problems) and associated human tensions (distress, aggression, depression, torture, despair) are and will likely become a more common denominator in people's lifes in the future (Horner-Dixon 1991; McMichael et al. 2008). Sustainability science is in critical need of qualitative and quantitative approaches to address these and many more consequences that result from global change, to facilitate citizens' comprehension of the scientific and potential policy dimensions of environmental change, especially because it is the general public that bears the costs of transformation and adaptation measures (Angeler 2016).

Here, metal is explored as one qualitative tool that provides a critical thinking and education model about such complex challenges. Artists and scientists are increasingly collaborating (e.g., EcoArt movement) to communicate the nature of problems, heighten awareness of ecological concerns, search for new solutions, and design ecological activity to enable public action (Kagan 2014). A series of approaches is used to communicate environmental change problems, ranging from realistic (e.g. photography) to abstract, often aiming to elicit human tensions (Peeples 2011). Shock tactics are often used to reinforce the surprise component and stimulate people's learning and long-term memory formation (Timms 2004, Lisman and Grace 2005). With regards to art, and similar to the Dada movement in the early twentieth century, it has been argued that forms of heavy metal have systematically transgressed the boundaries of the accepted in the auditory arts (Kahn-Harris 2007), and other music forms (e.g., post-punk, New Complexity School) might similarly deviate from these boundaries. This suggests that metal can symbolize artistically when change potentially takes people out of comfort zones.

Although not unique to metal music alone, individual subgenres of metal (Table 2) have song structures that become allegorical to and can symbolize specific aspects of human tensions associated with disturbances in social-ecological systems (e.g., natural disasters, terrorist attacks, humanitarian crises; see below). Songs from these subgenres can be linked with these specific social-ecological system challenges artistically, although these specific links are entirely subjective, as many artistic expressions are in general. I showcase this potential with selected examples (Table 3) from a potentially vast spectrum of application. Note that band and song names are of subordinate importance in symbolizing these sentiments. That is, although the songs were not always written to intentionally make the connection to environmental sustainability challenges, it is possible to draw a comparison between the sounds and lyrics the music inspires in many people's emotions and sustainability challenges. In the examples below, emphasis is placed on contextualizing metal songs with specific environmental change challenges from which emotional reactions in people possibly ensue. The metal allegories comprise an approach, based on the visual arts (Thomsen 2015), which has potential to reconceptualize "hearing" as "questioning". That is, the allegorical expression of environmental change issues through metal might trigger a chain of questioning: for instance, what is environmental change and why do we need to study it? How do these challenges relate to sustainability? What are elements of uncertainty and surprise, and how do they manifest? This process can improve learning and connect people more closely with environmental sustainability issues (e.g., Ryan 2001; Angeler 2016). A combination of metal with visual underpinnings (e.g., photography; Thomsen 2015) may further bolster people's connection to environmental change problems. Also, there is precedence in the use 


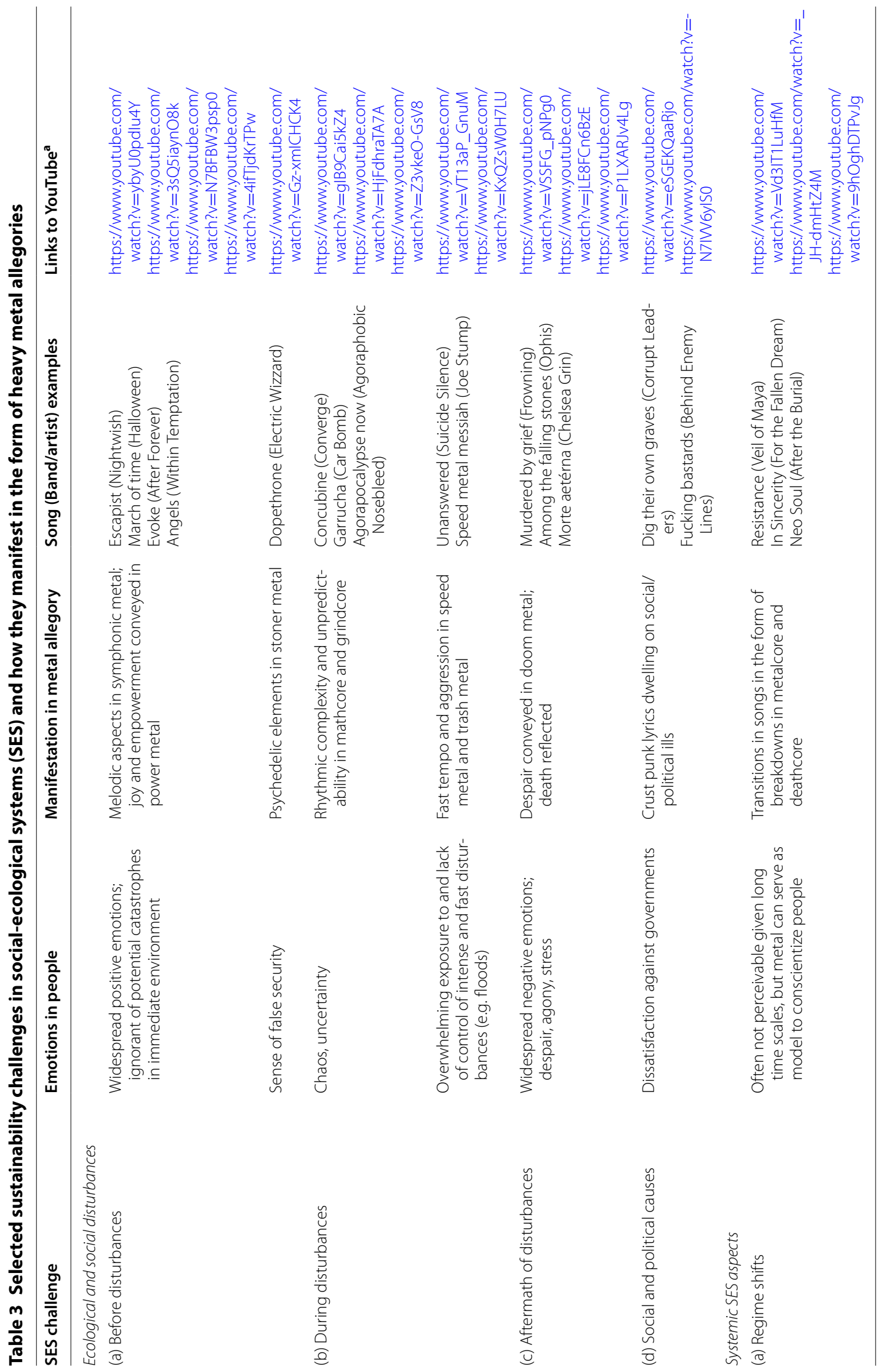




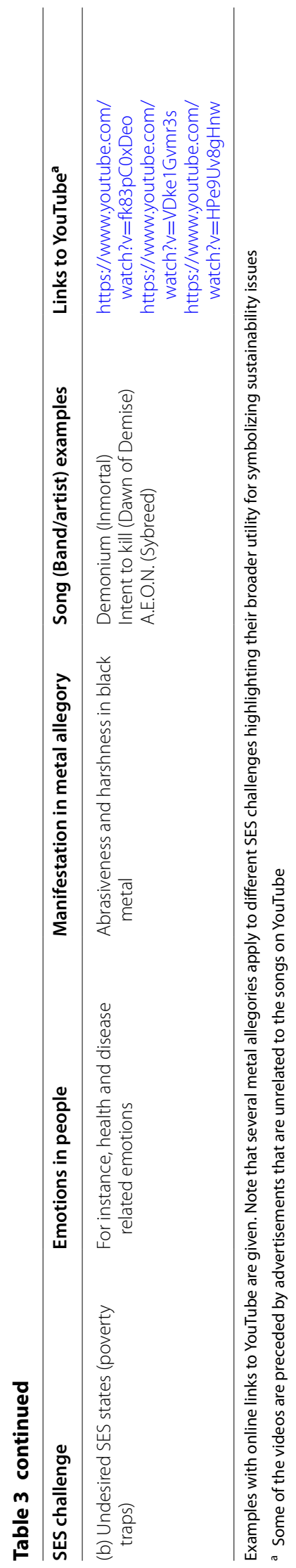


of metal sound tracks to provide auditory support in war (Black Hawk Down), horror (Valentine), action/science fiction (The Matrix), or fantasy (The Crow) movies and film series (Resident Evil). O’Brien (2012) deals specifically with the use of metal in combat movies.

\section{Metal, human tensions and environmental sustainability}

Disturbances as manifestations of social-ecological system dynamics can be associated with a variety of metal subgenres that are allegorical to human emotions. That is, these subgenres have the necessary diversity to characterize allegorically distinct sustainability issues and experiences and sentiments of people prior, during and after disturbances.

In a social-ecological context, imagine a society that lives in a peaceful environment, urban or rural, where their basic requirements for livelihood are covered, including recreational and other services provided by nature. People live with a sense of relative security and happiness. These conditions and sentiments can be expressed with the more melodic symphonic metal subgenre or power metal that seeks to empower the listener and inspire joy and courage. However, the sense of security can be false when people take their comfort for granted. Occasionally sludge metal, and stoner metal with its psychedelic elements, which reflects a temporary altered state of consciousness induced by the consumption of psychedelic drugs, can symbolize feelings of false reality or security as catastrophes can happen at any time.

With climate change, the frequency, duration and magnitude of disturbances are altered. For instance, devastating wildfires or extreme precipitation events that result in flashfloods occur more often in a changing climate (Christensen and Christensen 2003; Gillett et al. 2004). The devastation of torrential floods or wildfires occurs relatively fast, causing death and destroying the basis of people's livelihoods. Metal genres with fast tempo and overall aggression in sound and vocals, like speed metal or trash metal, can symbolize the fast devastation when floods or fires unleash and peoples reactions to these catastrophes. People's despair, agony and suffering in the aftermath of these disturbances becomes allegorical to many sentiments that doom metal inspires with slower tempos, low-tuned guitars and thick/heavy sounds.

Similar sentiments can be expressed with social disturbances. The world currently witnesses large scale human migrations caused by war. The sense of agony of people fleeing their countries with an associated loss in economic and social potential, culminating in humanitarian catastrophe, can be brought to mind with the sentiments death doom and funeral doom inspire. Crust punk and grindcore, which consciously emphasize political and social ills, can symbolize the sources of conflict that can result from corrupted and/or authoritarian governance regimes.

Chaos and uncertainty are high during and immediately after disturbances, resulting in discomfort from not knowing how the disturbance will end or what the future holds. Uncertainty and chaos may be associated with the patterns of mathcore's, grindcore's, and progressive metal's rhythmic complexity. These subgenres are characterized by unusual time signatures, atonality and dissonance in the manifestation of song elements that are reminiscent of chaos. The listener is constantly challenged to digest and anticipate dynamically interacting and often antithetical sound patterns and rhythm structures. These metal subgenres, along with other types of media and art, have therefore high potential to increase people's awareness about the sentiments and behavior of uncertainty and chaos that people may experience as a result of natural disasters.

Similar applications of metal allegories can be used in other contexts, highlighting their broader use to symbolize disturbances in social-ecological systems. There is a wide range of social issues that lend themselves to the emotional content of metal, such as the stresses particular to urban living for instance, recurring overarching problems in public transportation during rush hours, attacks in schools, or broad-scale terrorist massacres in urban public places.

In social-ecological systems disturbances can ultimately lead to wider systemic changes resulting in substantial reorganization of the system's structure, function and dynamics (i.e., regime shifts). Regime shifts occur when for example a shallow lake with clear water and submerged vegetation shifts into a nutrient-enriched, turbid-water regime with frequent algal bloom outbreaks. This nutrient-enriched regime is stable, meaning that the lake will not return to a clear-water regime without substantial management. Such systemic changes of socialecological systems can be explored through metal songs from distinct subgenres. Regime shifts per se that characterize the non-linear transitions between system regimes can be characterized with metalcore and deathcore songs. These songs symbolize the dynamism inherent in non-linear transitions in the form of "breakdowns" that introduce sudden changes in beat and rhythm patterns in a song; that is, breakdowns in metalcore and deathcore is figurative of the existence of and can inspire people about dynamic changes between alternative regimes in social-ecological systems. A further systemic aspect of social-ecological system change becomes evident when systems have shifted and locked in a new regime after a disturbance threshold has been passed. Similarly to the above examples of sentiments people may experience in the aftermath of a disturbance, metal allegories based on 
more abrasive and harsher black metal, can be used to characterize the persistence of an undesired post-disturbance regime; for instance, when a system locks in poverty traps, which are characterized by limited access to credit and capital markets, extreme environmental degradation (which depletes agricultural production potential), corrupt governance, capital flight, poor education systems, disease ecology, lack of public health care, war and poor infrastructure (Bonds et al. 2010). To demonstrate such cases, metal can be used to increase people's awareness that systems are often not able to rebound from disturbances, but rather become trapped in an undesirable regime for humans, and which are very difficult to escape (e.g., Cinner et al. 2009).

\section{Synthesis}

The preceding sections explored hitherto nonexistent links between metal, an auditory art, complex adaptive systems and environmental sustainability science along two independent dimensions; that is, from a socio-musicological systems point of view and an environmental education/awareness perspective (Fig. 1). These lines of inquiry show that metal as an art form has potential to describe distinct and independent facets of the complexity of systems of people and nature. The paper concludes with an examination of the overarching implications that may derive from the merger of these independent explorations.

There are many different complex adaptive systems in systems of people and nature (Sundstrom et al. 2014). Arguably, art comprises a complex system that is embedded in a broader social-cultural-environmental complex adaptive system (Fig. 1). Within the arts there are many forms and genres that might be nested and interacting complex adaptive systems. Using heavy metal as an example, this paper shows how a musical form can become its own complex adaptive system or socio-musicological systems. Such systems are often artificially separated in scientific research, which impedes the development of appropriate models and knowledge of system dynamics. The emergence of metal not only reflects cultural change in modern societies, its dynamics follow those described for complex adaptive systems. Metal thus provides a valuable addition to complex adaptive systems research and further highlights that considering the arts as a form of complex adaptive system is long overdue. The bottom line is that it is uninformative to consider the arts and sciences as discrete units (Friedenwald-Fishman 2011). The arts and the basic and applied dimensions of science are integral to humanity. People cannot be understood as separate from our environment, be it ecological, cultural, political.
Heavy metal diversifies and evolves fast in response to rapidly changing social and technological factors. These dynamics mirror the equally rapid changes in the ways modern human societies interact with the environment, and which are driven by the same factors (exemplified by the social-ecological systems dimension in Fig. 1). However, the interactions between people and the environment have reached dimensions that have become potentially detrimental to the planets capacity to support humankind (Rockström et al. 2009). Although it is highly uncertain how current patterns of human-environment interactions will unfold in the future, several socialecological challenges, as those exemplified in this paper, will likely interfere with mankind's welfare and the way humans interact with each other. Tribal societies have for thousands of years used music as an art form to express sentiments about and show emotional responses to phenomena observed in nature (Morely 2013). The counterculture arts (Dada, Surrealism) of the 1920s in Europe both informed and were informed by socio-culturalpolitical revolutions, including rejection of traditional modes of authority and conservative societies. Those revolutions in the cultural landscape were connected partly to the music that helped drive those changes, as well as reflected those changes (LeBaron 2002). Similar dynamics can be observed in this Millennium, exemplified with the dynamics of heavy metal as a complex socio-musicological system.

Exploring apparently unrelated connections between different disciplines and art movements, such as surrealism and quantum physics (Parkinson 2008), or mental illness and political leadership (Ghaemi 2011), have shown opportunities for scientific inquiry that are not commonly practiced in academic circles. However, such lines of exploration open ways for a broader understanding of complex adaptive systems and have potential to inform our ability to understand, predict, and cope with their dynamics and change. It was the aim of this paper to show that the use of heavy metal as an art form can contribute to such an endeavor, exploring the use of the music to inform two different areas of scientific inquiry, complexity and sustainability science. While novel in itself, the independent discussions of the contribution of metal to the basic and applied sciences begs the question how metal as a socio-musicological system (Dimension 1; Fig. 1) and as a tool for environmental education (Dimension 2) are linked. Both dimensions entrain with each other and a plethora of other dimensions of socialecological system dynamics not discussed in this paper to lead to the emergence of a broader social-culturalenvironmental system (Fig. 1). The emanation of such a broader system cannot be explained simply by the sum of 
individual explorations of dimensions. In these dynamics the individual dimensions behave like actors that weave together and inform cultural, social and environmental facets in a broader complex adaptive system. Imagine a human body where the central nervous system modulates sensory, visual, auditory and olfactory stimuli. These processes are likely independent from each other and operate in distinct lobes of the brain, yet all are integral to the functioning of human live and coordinated by complex adaptive processes of the central nervous system. Music and its application to complexity and sustainability science can be similarly considered as independent; however, both are integral to human society and coordinated by broader social-cultural-environmental dynamics (Fig. 1). The patterns described for the brain and socialcultural-environmental systems are analogous and lay at the very heart of complex adaptive system dynamics described in this paper.

In conclusion, heavy metal, complexity theory, and sustainability science are not mutually exclusive. Together they become poietic in Plato's sense; that is, bringing into existence the previously inexistent in endeavors to better understand the broader dynamics of and the multidimensional ramification of environmental change on complex systems of people and nature. Progress in human culture occurs in concert with, rather than independently of, art, science and the environment. Thus, there is need for integral models for envisioning and potentially dealing with the complexity of fast-changing social-ecological baselines that currently affect and are affected by humanity. Connecting the arts and sciences has enormous potential to provide learning opportunities about the known unknowns and the unknown unknowns associated with global change problems. Combining apparently unrelated entities, like heavy metal music and different scientific disciplines, may help people better envision and boost critical thinking about the complexity that drives the dynamics of broader social-cultural-environmental systems. Such approaches are necessary to facilitate citizens' comprehension of the scientific and potential policy dimensions of environmental change, especially because it is the general public that bears the costs of a transforming planet.

\begin{abstract}
Acknowledgements
This paper has been conceived of and written during a period of personal turmoil. I thank my family, María José, Michael and Carmen, for their unconditional love, and my friends, colleagues, students and health care professionals for support. Their help has converted my crisis into opportunity. Feedback by Shana Sundstrom, María José García, Sophia Renes, Magnus Nilsson, Didier Baho, Stina Drakare, and anonymous reviewers is acknowledged. The Swedish Research Councils VR and Formas provided financial support. This paper is dedicated to my late grandmother, Theresa Camilleri.
\end{abstract}

\section{Competing interests}

The author declares that he has no competing interests.
Received: 24 May 2016 Accepted: 11 September 2016

Published online: 21 September 2016

\section{References}

Adger WN, Eakin H, Winkels A (2009) Nested and teleconnected vulnerabilities to environmental change. Front Ecol Environ 7:150-157

Allen CR, Angeler DG, Garmestani AS, Gunderson LH, Holling CS (2014) Panarchy: theory and applications. Ecosystems 17:578-589

Angeler DG (2016) Viewing biodiversity through the lens of science... and art! SpringerPlus 5:1174. doi:10.1186/s40064-016-2831-z

Angeler DG, Sundstrom SM, Allen CR (2016) Deathcore, creativity and scientific thinking. Res Ideas Outcomes 2:e8796. doi:10.3897/rio.2.e8796

Bachelard G (1934) Le nouvel esprit scientifique. Alcan, Paris

Bachelard G (1936) Le surrationalisme. Inquisitions 1:1-6

BBC (2003) Sesame street breaks Iraqi POWs. http://news.bbc.co.uk/go/pr/fr//2/hi/middle_east/3042907.stm

Berkes F, Colding J, Folke C (2003) Navigating social-ecological systems. Cambridge University Press, Cambridge

Bonds MH, Keenan DC, Rohani P, Sachs JD (2010) Poverty trap formed by the ecology of infectious diseases. Proc R Soc Lond B 277:1185-1192

Breton A (1936) Crise de l'objet. Cahiers d'Art 1-2:21-26

Brown AR (2011) Heavy genealogy: mapping the currents, contraflows and conflicts of the emergent field of metal studies, 1978-2010. J Cult Res $15: 213-242$

Christensen JH, Christensen OB (2003) Climate modelling: severe summertime flooding in Europe. Nature 421:805-806

Cinner JE, Daw T, McClanahan TR (2009) Socioeconomic factors that affect artisanal fishers' readiness to exit a declining fishery. Cons Biol 23:124-130

Folke C, Carpenter S, Elmqvist T, Gunderson L, Holling CS, Walker B (2002) Resilience and sustainable development: building adaptive capacity in a world of transformations. Ambio 31:437-440

Folke C, Carpenter S, Walker B, Scheffer M, Elmqvist T, Gunderson L, Holling CS (2004) Regime shifts, resilience, and biodiversity in ecosystem management. Annu Rev Ecol Evol Syst 35:557-581

Frenken K (2006) A fitness landscape approach to technological complexity, modularity, and vertical disintegration. Struct Change Econ Dyn 17:288-305

Friedenwald-Fishman E (2011) No art! No social change! No innovation economy! Stanford Soc Inno Rev, May 26, 2011. [online] Url: http://ssir. org/articles/entry/no_art_no_social_change._no_innovation_economy

Ghaemi N (2011) A first-rate madness: uncovering the links between leadership and mental illness. Penguin Press, London

Gillett NP, Weaver AJ, Zwiers FW, Flannigan MD (2004) Detecting the effect of climate change on Canadian forest fires. Geophys Res Lett 31:L18211. doi :10.1029/2004GL020876

Hickam B (2014) Amalgamated anecdotes: perspectives on the history of metal music and culture studies. Metal Music Stud 1:5-23

Holland JH (2014) Complexity — a very short introduction. Oxford University Press, Oxford

Holling CS (1973) Resilience and stability of ecological systems. Annu Rev Ecol Syst 4:1-23

Horner-Dixon TF (1991) On the threshold: environmental changes as causes of acute conflict. Int Secur 16:76-116

Hughes TP, Carpenter S, Rockström J, Scheffer M, Walker B (2013) Multiscale regime shifts and planetary boundaries. Trends Ecol Evol 28:389-395

Kagan S (2014) The practice of ecological art. Plastic_-art and science, 4. Online: $\mathrm{http}$ ://art-science.univ-paris1.fr/plastik/document.php?id=866. ISSN 2101-0323

Kahn-Harris K (2007) Extreme metal: music and culture on the edge. Berg, Oxford

Kates RW, Clark WC, Corell R, Hall JM, Jaeger CC, Lowe I, McCarthy JJ, Schellnhuber HJ, Bolin B, Dickson NM, Faucheux S, Gallopin GC, Grübler A Huntley B, Jäger J, Jodha NS, Kasperson RE, Mabogunje A, Matson P, Mooney H, Moore B, O'Riordan T, Svedin U (2001) Sustainability science. Science 292:641-642

Konow D (2002) Bang your head: the rise and fall of heavy metal. First Printing 2006. Plexus Publishing Limited, London, UK

Lansing JS (2003) Complex adaptive systems. Annu Rev Anthropol 32:183-204 
LeBaron A (2002) Reflections of surrealism in postmodern musics. In: Lochhead J, Auner J (eds) Postmodern music/postmodern thought. Routledge, New York, pp 27-83

Leskovec J, Adamic LA, Huberman BA (2007) The dynamics of viral marketing ACM Trans Web 1(1):Article 5. doi:10.1145/1232722.1232727

Levine EG, Levine SK (2011) Art in action: expressive arts therapy and social change. Jessica Kingsley Publishers, London

Lisman JE, Grace AA (2005) The hippocampal-VTA loop: controlling the entry of information into long-term memory. Neuron 46:703-713

McMichael AJ, Friel S, Nyong A, Corvalan C (2008) Global environmental change and health: impacts, inequalities, and the health sector. Brit Med J 336:191-194

Meadows DH (2008) Thinking in systems. Chelsea Green Publishing, White River Junction

Morely I (2013) The prehistory of music. Oxford University Press, Oxford

O'Brien WJ (2012) Music in American combat films: a critical study. McFarland $\&$ Co Inc Publishers, Jefferson

Parkinson G (2008) Surrealism, art and modern science. Yale University Press, New Haven

Patel AD (2010) Music, biological evolution, and the brain. In: Bailar M (ed) Emerging disciplines. Rice University Press, Houston, pp 91-144

Peeples J (2011) Toxic sublime: imaging contaminated landscapes. Environ Comm 5:373-392

Ratner C (2002) Subjectivity and objectivity in qualitative methodology. Forum Qual Sozialforschung 3(3):art16

Rinia EJ, Van Leeuwen TN, Bruins EE, Van Vuren HG, Van Raan AF (2002) Measuring knowledge transfer between fields of science. Scientometrics 54(3):347-362

Rist L, Felton A, Nyström M, Troell M, Sponseller RA, Bengtsson J, Österblom H, Lindborg R, Tidåker P, Angeler DG, Milestad R, Moen J (2014) Applying resilience thinking to production ecosystems. Ecosphere 5:art73. doi:10.1890/ES13-00330.1

Rockström J, Steffen W, Noone K, Persson Å, Chapin FS, Lambin E et al (2009) Planetary boundaries: exploring the safe operating space for humanity. Ecol Soc 14(2):32. http://www.ecologyandsociety.org/vol14/iss2/art32/
Ryan VL (2001) The physiological sublime: Burke's critique of reason. J Hist Ideas 62:265-279

Schmaltz RM (2016) Bang your head: using heavy metal music to promote scientific thinking in the classroom. Front Psychol 7:146

Seppi M, Stoycheva G (2015) Heavy metal music and culture in rapidly changing global markets. Bachelor's thesis. Jamk University of Applied Sciences, Finland

Sharpe-Young G (2007) Metal the definitive guide. Jawbone Press, London Stanton AL, Ramsey E, Seybolt PJ, Elliott CM (2012) Cultural sociology of the Middle East, Asia, and Africa: an encyclopedia. Sage Publishing, Thousand Oaks

Sterman JD (1994) Learning in and about complex systems. Syst Dynam Rev 10:291-330

Sundstrom SM, Angeler DG, Garmestani AS, García JH, Allen CR (2014) Transdisciplinary application of cross-scale resilience. Sustainability 6:6925-6948

Thomsen D (2015) Seeing is questioning: prompting sustainability discourses through an evocative visual agenda. Ecol Soc 20(4):9 [online]. doi:10.5751/ES-07925-200409

Timms P (2004) What's wrong with contemporary art?. University of New South Wales Press, Sydney

Trilling D (2007) Rocking the world. New Statesman 136:38-40

Tsatsishvili V (2011) Automatic subgenre classification of heavy metal music. Master thesis. Music, Mind \& Technology. University of Jyväskyla, Finland

Varas-Díaz N, Rivera-Segarra E, Rivera-Medina CL, Mendoza S, GonzalezSepúlveda O (2014) Predictors of communal formation in a small heavy metal scene: Puerto Rico as a case study. Metal Music Stud 1:87-103

Walker B, Holling CS, Carpenter SR, Kinzig A (2004) Resilience, adaptability and transformability in social-ecological systems. Ecol Soc 9(2):5. http://www. ecologyandsociety.org/vol9/iss2/art5/

Wallach J (2005) Underground rock music and democratization in Indonesia. World Lit Today 79:16-20

Walser R (1993) Running with the devil: Power, gender, and madness in heavy metal music. Wesleyan University Press, Middleton

Weinstein D (1991) Heavy metal: a cultural sociology. Macmillan, New York

\section{Submit your manuscript to a SpringerOpen ${ }^{\circ}$ journal and benefit from:}

- Convenient online submission

- Rigorous peer review

- Immediate publication on acceptance

- Open access: articles freely available online

- High visibility within the field

- Retaining the copyright to your article

Submit your next manuscript at springeropen.com 